Supporting information for:

\title{
A convenient chemoenzymatic preparation of chimeric macrocyclic peptide antibiotics with potent activity against Gram-negative pathogens
}

Thomas M. Wood, ${ }^{1,2, \ddagger}$ Cornelis J. Slingerland, ${ }^{1, \ddagger}$ Nathaniel I. Martin ${ }^{1, *}$

${ }^{1}$ Biological Chemistry Group, Institute of Biology Leiden, Leiden University, Sylviusweg 72, 2333 BE

Leiden, The Netherlands. *n.i.martin@biology.leidenuniv.nl

2Department of Chemical Biology \& Drug Discovery, Utrecht Institute for Pharmaceutical Sciences, Utrecht University, Universiteitsweg 99, 3584 CG Utrecht, The Netherlands.

${ }^{\ddagger}$ These authors contributed equally to this work.

\section{Table of contents}

S2 Reagents and General Methods

S3-4 Synthesis of PMEN/PMBN and PMEH azide building blocks

S4 Protocol for preparation of triazoles 9a-c, 12

S5 Antibacterial assay

S5 HRMS analysis for new compounds

S6-11 Analytical HPLC traces

S12 References 


\section{Reagents and General Procedures}

All reagents employed were of American Chemical Society (ACS) grade or finer and were used without further purification unless otherwise stated. Fmoc-Dab(Boc)-OH, Fmoc-D-Dab(Boc)-OH, Fmoc-Hse(Trt)$\mathrm{OH}$, Fmoc-Tle-OH and Fmoc-Glu-OAllyl were obtained from Combi-Blocks. For compound characterization HRMS analysis was performed on a Shimadzu Nexera X2 UHPLC system with a Waters Acquity HSS C18 column $(2.1 \times 100 \mathrm{~mm}, 1.8 \mu \mathrm{m})$ at $30^{\circ} \mathrm{C}$ and equipped with a diode array detector. The following solvent system, at a flow rate of $0.5 \mathrm{~mL} / \mathrm{min}$, was used: solvent $\mathrm{A}, 0.1 \%$ formic acid in water; solvent B, $0.1 \%$ formic acid in acetonitrile. Gradient elution was as follows: 95:5 (A/B) for $1 \mathrm{~min}, 95: 5$ to 15:85 (A/B) over $6 \mathrm{~min}, 15: 85$ to $0: 100(A / B)$ over $1 \mathrm{~min}, 0: 100(\mathrm{~A} / \mathrm{B})$ for $3 \mathrm{~min}$, then reversion back to 95:5 (A/B) for $3 \mathrm{~min}$. This system was connected to a Shimadzu 9030 QTOF mass spectrometer (ESI ionisation) calibrated internally with Agilent's API-TOF reference mass solution kit (5.0 mM purine, 100.0 $\mathrm{mM}$ ammonium trifluoroacetate and $2.5 \mathrm{mM}$ hexakis $(1 \mathrm{H}, 1 \mathrm{H}, 3 \mathrm{H}$-tetrafluoropropoxy)phosphazine) diluted to achieve a mass count of 10000 .

Purity of the peptides was confirmed to be $\geq 95 \%$ by analytical RP-HPLC using a Shimadzu Prominence-i LC-2030 system with a Dr. Maisch ReproSil Gold $120 \mathrm{C} 18$ column $(4.6 \times 250 \mathrm{~mm}, 5 \mu \mathrm{m})$ at $30{ }^{\circ} \mathrm{C}$ and equipped with a UV detector monitoring at $214 \mathrm{~nm}$. The following solvent system, at a flow rate of 1 $\mathrm{mL} / \mathrm{min}$, was used: solvent $\mathrm{A}, 0.1 \%$ TFA in water/acetonitrile, $95 / 5$; solvent $\mathrm{B}, 0.1 \%$ TFA in water/acetonitrile, 5/95. Gradient elution was as follows: 95:5 (A/B) for $2 \mathrm{~min}, 95: 5$ to 0:100 (A/B) over 13 $\min , 0: 100(A / B)$ for $2 \mathrm{~min}$, then reversion back to 95:5 (A/B) over $1 \mathrm{~min}, 95: 5(\mathrm{~A} / \mathrm{B})$ for $2 \mathrm{~min}$.

The compounds were purified via preparative HPLC using a BESTA-Technik system with a Dr. Maisch Reprosil Gold 120 C18 column $(25 \times 250 \mathrm{~mm}, 10 \mu \mathrm{m})$ and equipped with a ECOM Flash UV detector monitoring at $214 \mathrm{~nm}$. The following solvent system, at a flow rate of $12 \mathrm{~mL} / \mathrm{min}$, was used: solvent $\mathrm{A}, 0.1$ $\%$ TFA in water/acetonitrile 95/5; solvent B, $0.1 \%$ TFA in water/acetonitrile 5/95. Gradient elution was as follows: $95: 5(\mathrm{~A} / \mathrm{B})$ for $2 \mathrm{~min}, 95: 5$ to $0: 100(\mathrm{~A} / \mathrm{B})$ over $45 \mathrm{~min}, 0: 100(\mathrm{~A} / \mathrm{B})$ for $2 \mathrm{~min}$, then reversion back to $95: 5(\mathrm{~A} / \mathrm{B})$ over $1 \mathrm{~min}, 95: 5(\mathrm{~A} / \mathrm{B})$ for $2 \mathrm{~min}$. 


\section{Synthesis}

Tetra-Boc-protected PMEN/PMBN $(\mathbf{4 a}, \mathbf{b})$

$\mathrm{PMEN}-B o c_{4}(\mathbf{4 a})$ and $\mathrm{PMBN}-\mathrm{Boc}_{4}(\mathbf{4 b})$ were prepared as previously described for $\mathrm{PMBN}-\mathrm{Boc}_{4}{ }^{1}$

PMEN azide derivatives (8a-c)

$P M E N-C_{2}-N_{3}(8 a)$

PMEN-Boc $_{4}(0.45 \mathrm{~g}, 0.34 \mathrm{mmol})$ was dissolved in DCM and DMF (8:2 v:v, $\left.10 \mathrm{~mL}\right)$. In a separate flask, 2azidoacetic acid $(68 \mathrm{mg}, 0.68 \mathrm{mmol})$ and BOP $(0.30 \mathrm{~g}, 0.68 \mathrm{mmol})$ were dissolved in DCM $(8 \mathrm{~mL})$. The mixture of 2-azidoacetic acid and BOP was then added to the PMEN-Boc 4 , followed by addition of DIPEA $(0.24 \mathrm{~mL}, 1.4 \mathrm{mmol})$. The reaction was left to stir overnight at $\mathrm{RT}$ under $\mathrm{N}_{2}$ atmosphere. After completion, the solvent was evaporated and the residue treated with TFA/TIPS/ $\mathrm{H}_{2} \mathrm{O}(95: 2.5: 2.5,8 \mathrm{~mL})$ for 1.5 hours. The reaction mixture was added to ice-cold MTBE/PE $(2 / 1,120 \mathrm{~mL})$. The resulting precipitate was washed with MTBE/PE (2/1). Crude peptide was lyophilized from $\mathrm{t}-\mathrm{BuOH} / \mathrm{H}_{2} \mathrm{O}$ and $\mathrm{HPLC}$ purified. Yield: $130 \mathrm{mg}, 0.13 \mathrm{mmol}, 39 \%$.

PMEN $-C_{5}-N_{3}(\mathbf{8 b})$

Compound was prepared as $\mathrm{PMEN}-\mathrm{C}_{2}-\mathrm{N}_{3}$, starting from $\mathrm{PMEN}(\mathrm{Boc}) 4$ and 5-azidopentanoic. Yield: 85 $\mathrm{mg}, 0.08 \mathrm{mmol}, 36 \%$.

PMEN-(PEG)3-N3 (8c)

Compound was prepared as $\mathrm{PMEN}-\mathrm{C}_{2}-\mathrm{N}_{3}$, starting from $\mathrm{PMEN}(\mathrm{Boc}) 4$ and 3-(2-(2-(2-azidoethoxy)ethoxy)ethoxy)propanoic acid. Yield: $120 \mathrm{mg}, 0.11 \mathrm{mmol}, 43 \%$.

Tri-Boc-protected PMEH (10)

$\mathrm{PMEH}-\mathrm{Boc}_{3}(\mathbf{1 0})$ was prepared and purified as previously described before for $\mathrm{PMBH}-\mathrm{Boc}_{3}{ }^{2}$ 
$\mathrm{PMEH}-\mathrm{C}_{2}-\mathrm{N}_{3}(\mathbf{1 1})$

$\mathrm{PMEH}_{-\mathrm{Boc}_{3}}(0.10 \mathrm{~g}, 0.10 \mathrm{mmol})$ was dissolved in DCM $(1 \mathrm{~mL})$. In a separate flask, 2-azidoacetic acid (20 $\mathrm{mg}, 0.19 \mathrm{mmol}$ ) was dissolved in DCM (1 mL) and 2,4,6-trimethylpyridine (50 uL, $0.38 \mathrm{mmol}$ ) was added. HCTU (79 mg, $0.19 \mathrm{mmol}) \mathrm{HOBt}(26 \mathrm{mg}, 0.19 \mathrm{mmol}$ ) were dissolved in DMF (1 mL) and added to the 2azidoacetic acid. Pre-activation was run for $5 \mathrm{~min}$. at RT, after which the mixture of 2-azidoacetic acid and coupling agent was added to the flask containing $\mathrm{PMEH}-\mathrm{Boc}_{3}$. The coupling reaction was run for 2-3 hours at RT under $\mathrm{N}_{2}$ atmosphere. When needed, additional 2-azidoacetic acid and coupling agents were added and reaction time was extended. Once complete, the solvent was evaporated and the residue treated with TFA/TIPS/ $\mathrm{H}_{2} \mathrm{O}(95: 2.5: 2.5,4 \mathrm{~mL})$ for 1.5 hours. The reaction mixture was added to ice-cold MTBE $(40 \mathrm{~mL})$. The resulting precipitate was washed with MTBE. Crude peptide was lyophilized from t$\mathrm{BuOH} / \mathrm{H}_{2} \mathrm{O}$ and HPLC purified. Yield: $41 \mathrm{mg}, 0.05 \mathrm{mmol}, 51 \%$.

\section{General procedure for formation of triazoles $(9 a-9 c, 12)$}

The alkyne modified peptidomimetic $\beta$-hairpin 7 was prepared using the same on-resin method employed in the synthesis of macrocycle 6 (see experimental section of main manuscript) but starting from Rink amide resin loaded with Fmoc-propargyl-glycine. The formation of the triazole linked bicyclic conjugates followed a previously described ${ }^{3}$ protocol: To a solution of the alkyne modified peptidomimetic $\beta$-hairpin 7 (20.0 mg, $12.1 \mathrm{mmol}, 1.0 \mathrm{eq})$ in ${ }^{\mathrm{t}} \mathrm{BuOH}: \mathrm{H}_{2} \mathrm{O}(1: 1,1 \mathrm{~mL})$ was added the polymyxin azide $(\mathbf{8 a}-\mathbf{8 c}, \mathbf{1 1})$ in 1.1 eq $(19-22 \mathrm{mg})$. Sodium ascorbate $(0.25 \mathrm{mg}, 1.2 \mathrm{mmol}, 0.1 \mathrm{eq})$ was then added followed by $\mathrm{CuSO}_{4} \cdot 5 \mathrm{H}_{2} \mathrm{O}$ $(0.15 \mathrm{mg}, 6 \mu \mathrm{mol}, 0.05 \mathrm{eq})$. The mixture was stirred at room temperature for 1 hour at which time complete disappearance of starting materials was generally observed. The solution was diluted in $4 \mathrm{~mL}$ $\mathrm{H}_{2} \mathrm{O}$ and directly subjected to RP-HPLC purification. Following lyophilization, the trialzole-linked conjugates were obtained as white powders in the following yields: 9a (18mg 56\%), 9b (18mg 55\%), 9c (19 $\mathrm{mg} \mathrm{60 \% ),} \mathrm{and} 12$ (21 mg 71\%). 


\section{Antibacterial Assays}

Minimum inhibitory concentrations (MICs) were determined by broth microdilution according to CLSI guidelines. ${ }^{4}$ Blood agar plates were inoculated with glycerol stocks of the chosen bacteria strains, followed by incubation for 16 hours at $37^{\circ} \mathrm{C}$. Cation adjusted Mueller-Hinton broth (CAMHB) containing 10 $\mathrm{mg} \cdot \mathrm{L}^{-1} \mathrm{Mg}^{2+}$ and $25 \mathrm{mg} \cdot \mathrm{L}^{-1} \mathrm{Ca}^{2+}$ was inoculated with individual colonies of the chosen bacteria, and incubated for 16 hours at 220 RPM. The peptides were dissolved in CAMHB, supplemented with polysorbate-80 (P-80 or Tween-80, sterile-filtered) at $0.002 \% \mathrm{v} / \mathrm{v}$ final concentration and serially diluted on polypropylene microtiter plates with a volume of $50 \mu \mathrm{L}$ per well. Inoculated CAMHB $\left(2 \times 10^{5} \mathrm{CFU} \cdot \mathrm{mL}^{-1}\right)$ was added to reach a total volume of $100 \mu \mathrm{L}$ per well. The microtiter plates were sealed with an adhesive membrane and after 16 hours of incubation at $37^{\circ} \mathrm{C}$ and $220 \mathrm{RPM}$ the wells were visually inspected for bacterial growth. All reported MIC values result from three or more measurements performed on multiple days.

Table S1. HRMS for all newly reported compounds

\begin{tabular}{|c|c|c|c|c|}
\hline Compound & Chemical formula & Calculated [M+H] & Calculated [M+2H]/2 & Measured \\
\hline $\mathbf{3 a}$ & $\mathrm{C}_{114} \mathrm{H}_{187} \mathrm{~N}_{33} \mathrm{O}_{32}$ & 2531.4098 & 1266.2088 & 1266.2085 \\
\hline $\mathbf{3 b}$ & $\mathrm{C}_{117} \mathrm{H}_{185} \mathrm{~N}_{33} \mathrm{O}_{32}$ & 2565.3942 & 1283.2010 & 1283.2017 \\
\hline $\mathbf{6}$ & $\mathrm{C}_{70} \mathrm{H}_{106} \mathrm{~N}_{18} \mathrm{O}_{20}$ & 1519.7909 & 760.3994 & 760.3994 \\
\hline $\mathbf{7}$ & $\mathrm{C}_{75} \mathrm{H}_{111} \mathrm{~N}_{19} \mathrm{O}_{21}$ & 1614.8280 & 807.9179 & 807.9180 \\
\hline $\mathbf{8 a}$ & $\mathrm{C}_{42} \mathrm{H}_{77} \mathrm{~N}_{17} \mathrm{O}_{12}$ & 1012.6016 & 506.8047 & 506.8043 \\
\hline $\mathbf{8 b}$ & $\mathrm{C}_{45} \mathrm{H}_{83} \mathrm{~N}_{17} \mathrm{O}_{12}$ & 1054.6485 & 527.8282 & 527.8278 \\
\hline $\mathbf{8 c}$ & $\mathrm{C}_{49} \mathrm{H}_{91} \mathrm{~N}_{17} \mathrm{O}_{15}$ & 1158.6959 & 579.8519 & 579.8515 \\
\hline $\mathbf{9 a}$ & $\mathrm{C}_{117} \mathrm{H}_{188} \mathrm{~N}_{36} \mathrm{O}_{33}$ & 2626.4218 & 1313.7148 & 1313.7106 \\
\hline $\mathbf{9 b}$ & $\mathrm{C}_{120} \mathrm{H}_{194} \mathrm{~N}_{36} \mathrm{O}_{33}$ & 2668.4687 & 1334.7383 & 1334.7359 \\
\hline $\mathbf{9 c}$ & $\mathrm{C}_{124} \mathrm{H}_{202} \mathrm{~N}_{36} \mathrm{O}_{36}$ & 2772.5161 & 1386.7619 & 1386.7555 \\
\hline $\mathbf{1 1}$ & $\mathrm{C}_{34} \mathrm{H}_{62} \mathrm{~N}_{14} \mathrm{O}_{9}$ & 811.4902 & 406.2491 & 811.4903 \\
\hline $\mathbf{1 2}$ & $\mathrm{C}_{109} \mathrm{H}_{173} \mathrm{~N}_{33} \mathrm{O}_{32}$ & 2425.3104 & 1213.1591 & 1213.1577 \\
\hline
\end{tabular}




\section{Analytical HPLC traces}

$3 a$

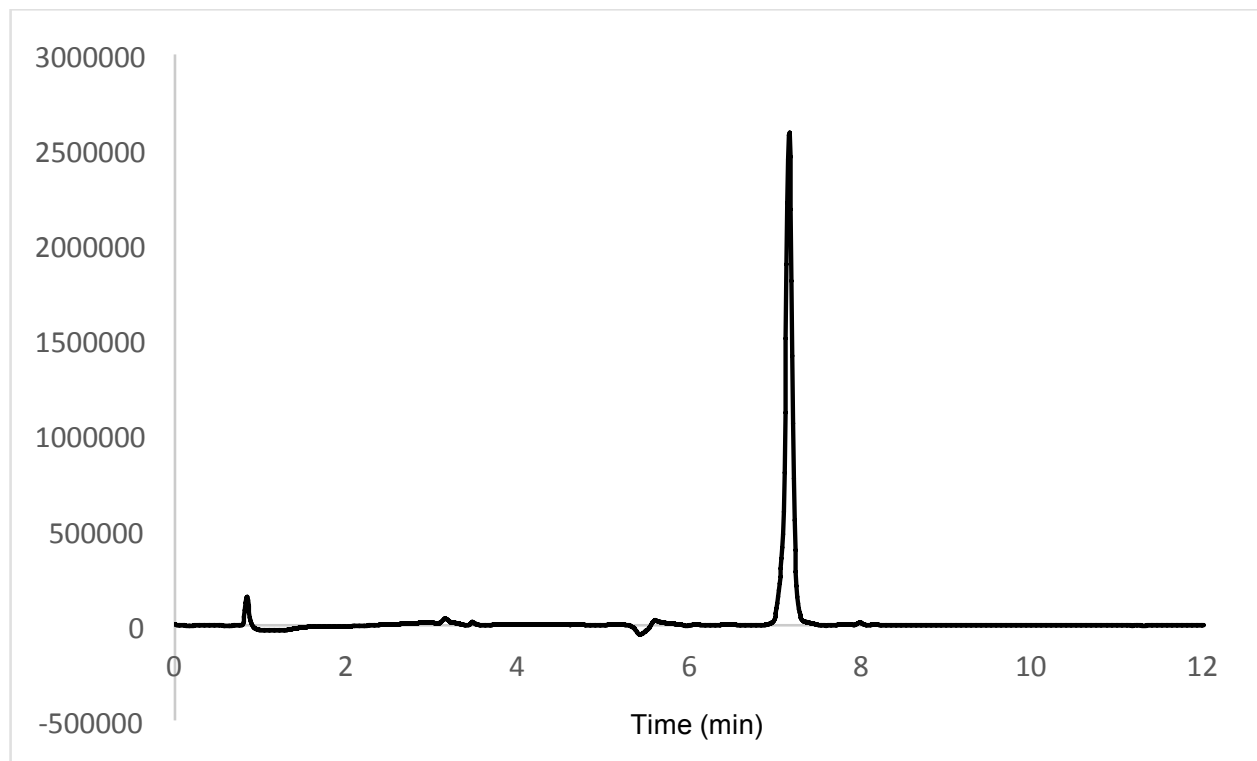

$3 b$

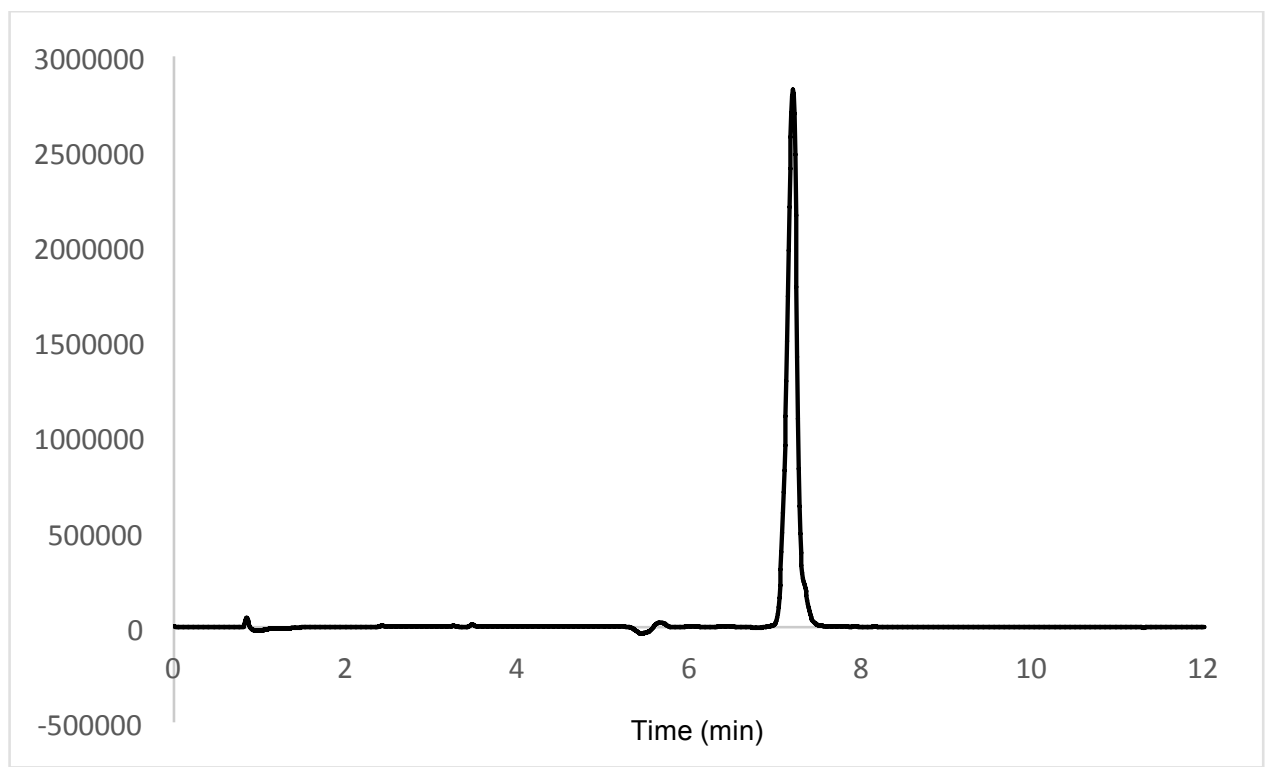




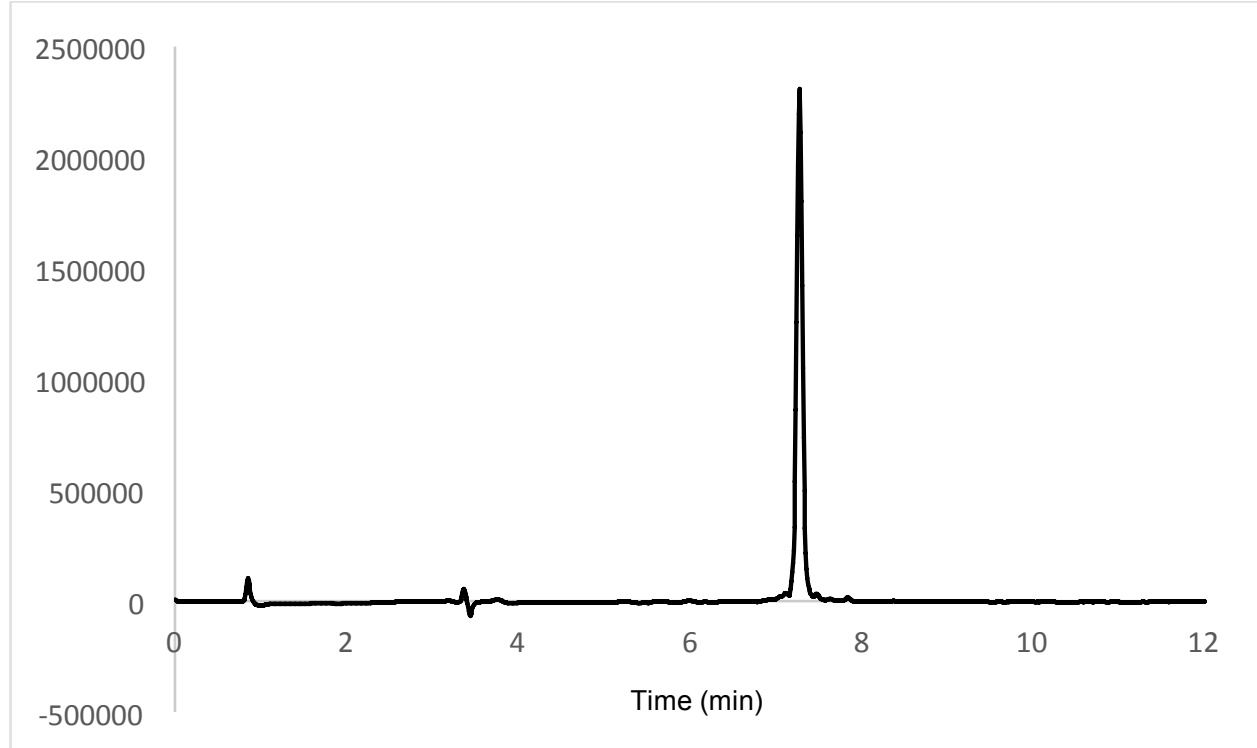

7

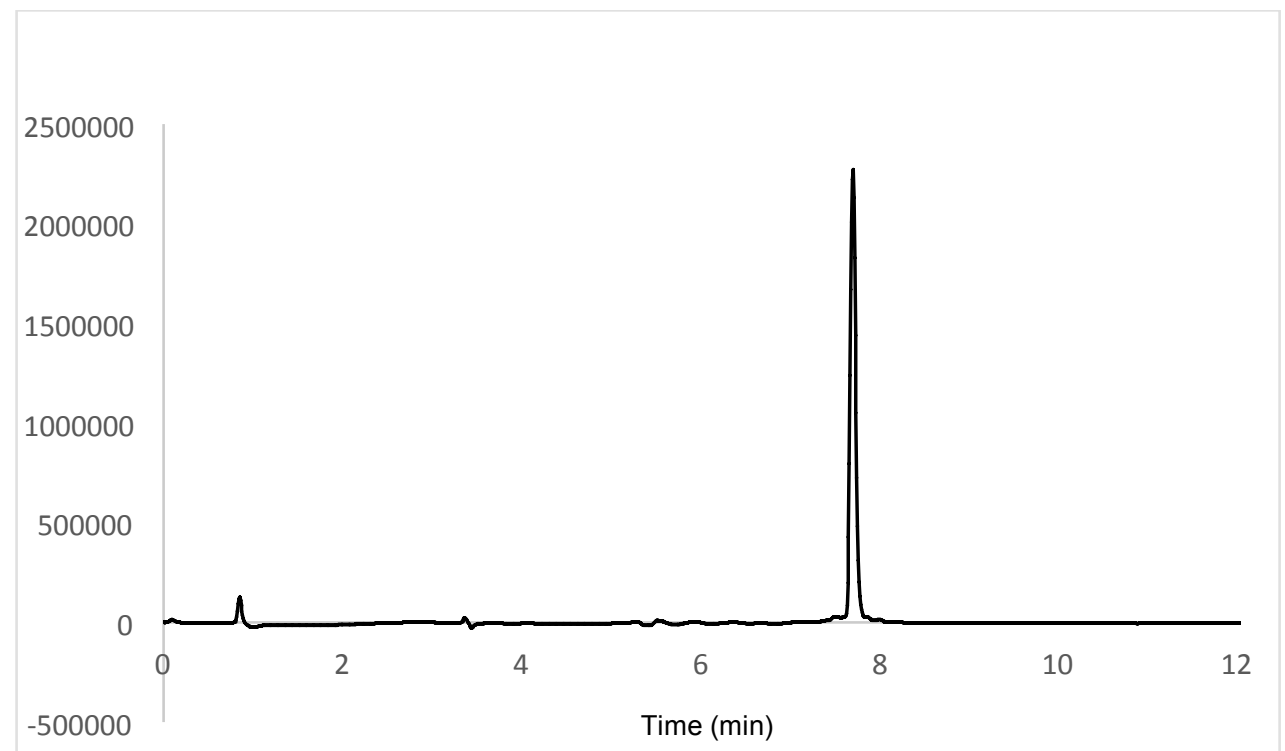


$8 a$

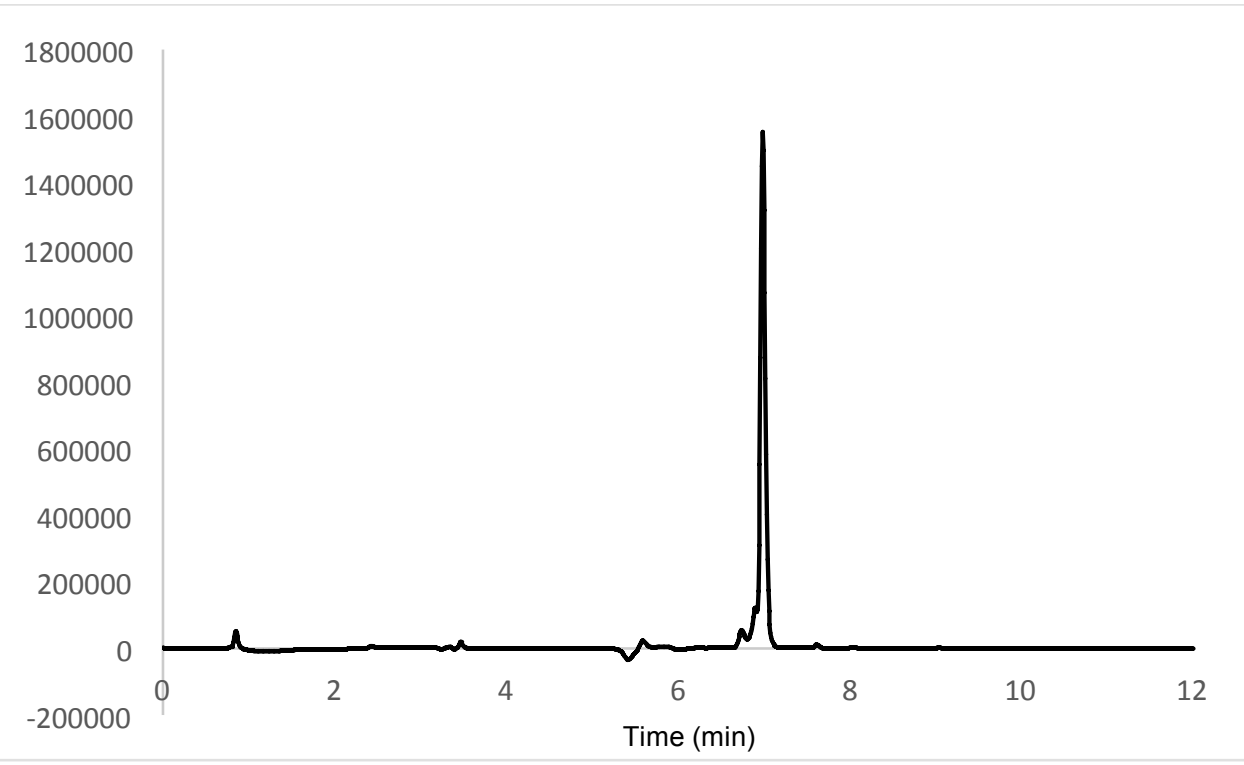

$8 b$

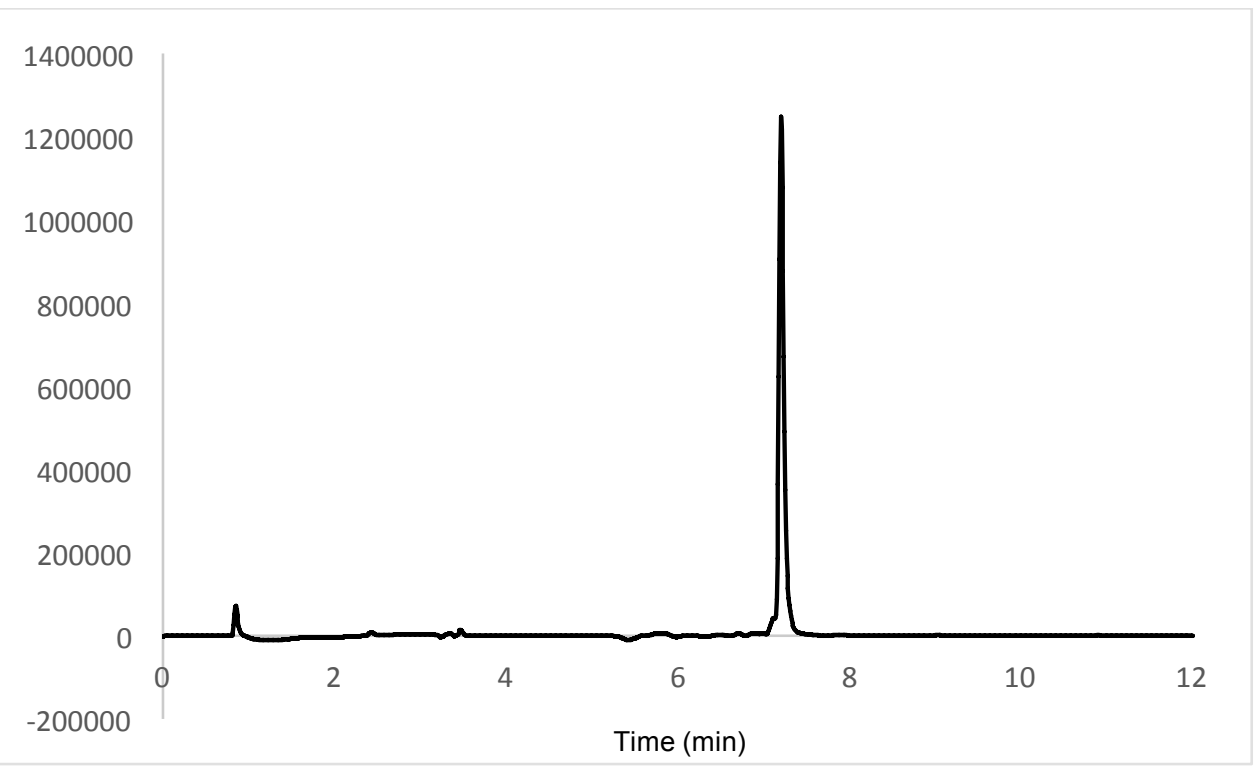


8c

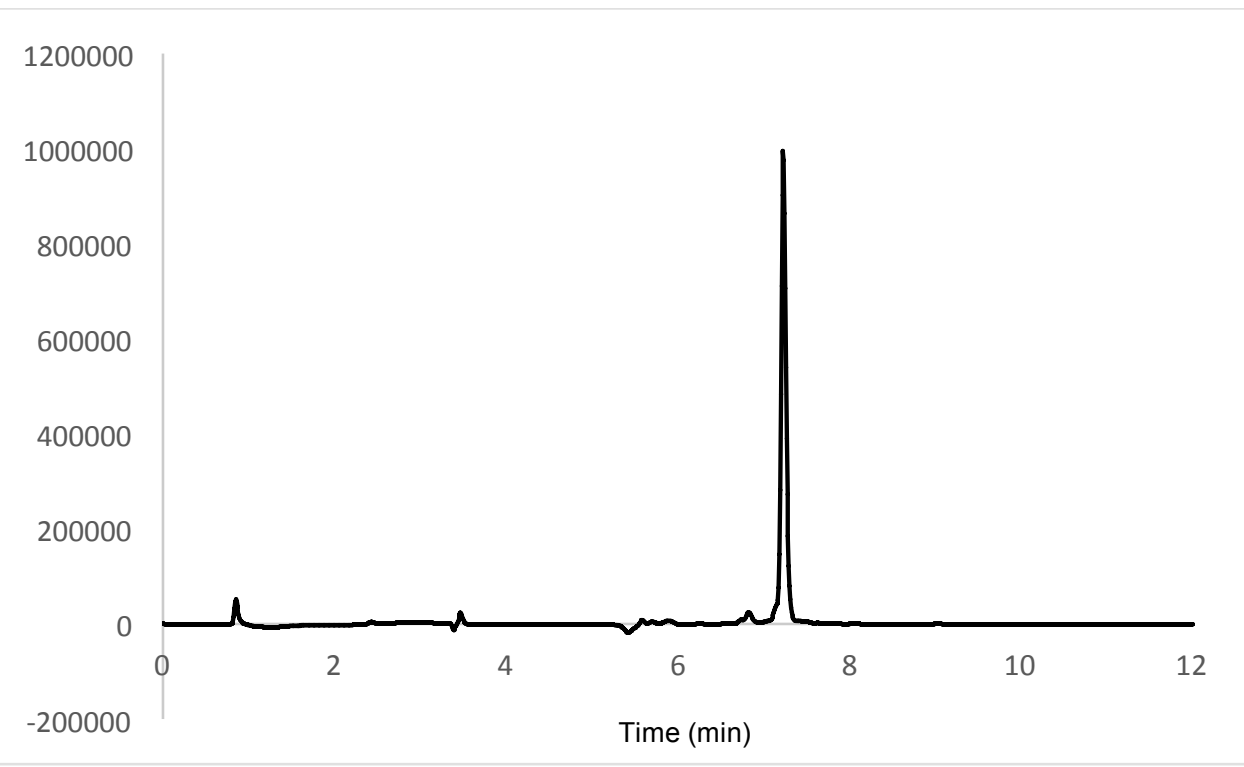

$9 a$

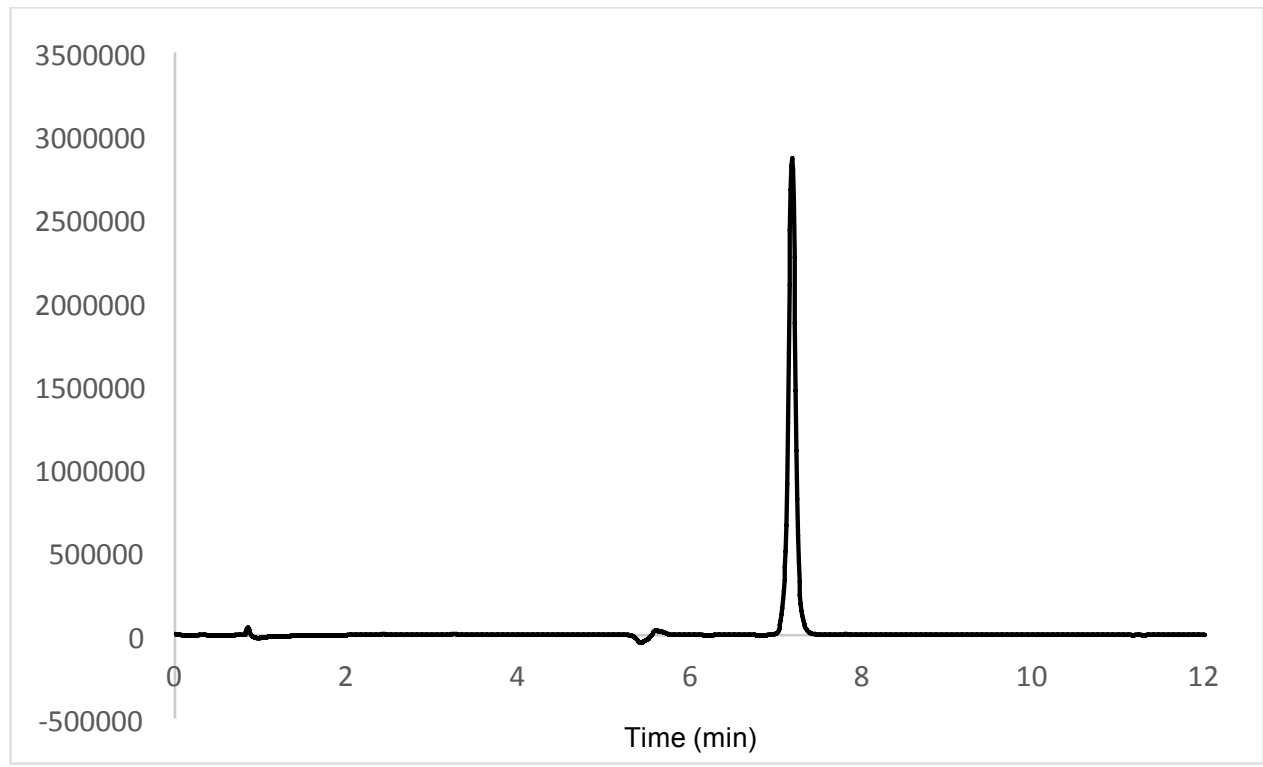


$9 b$

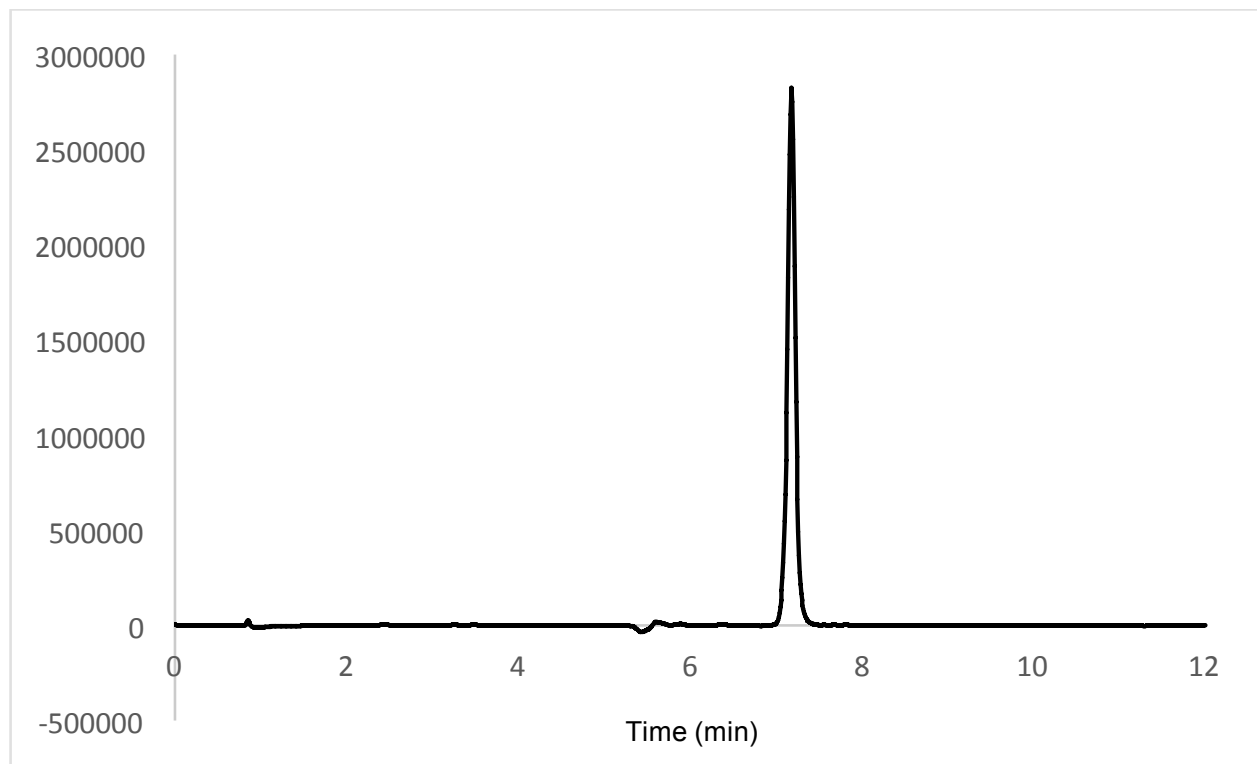

9c

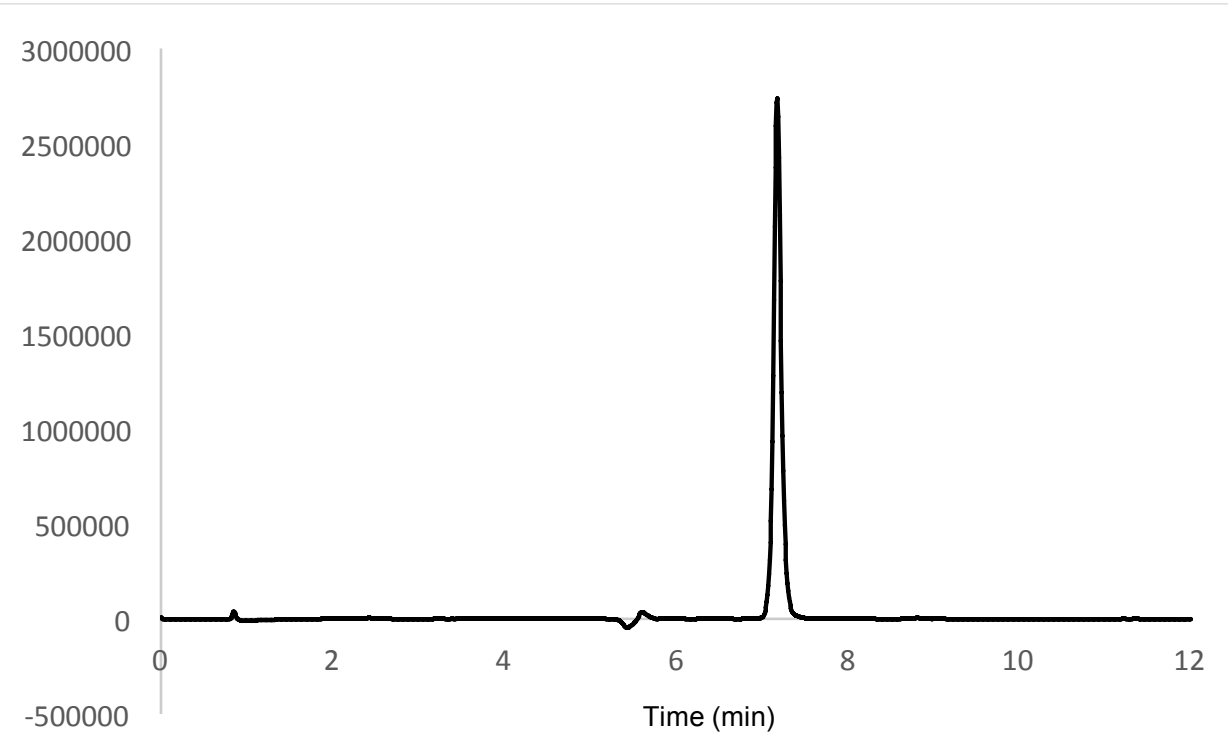




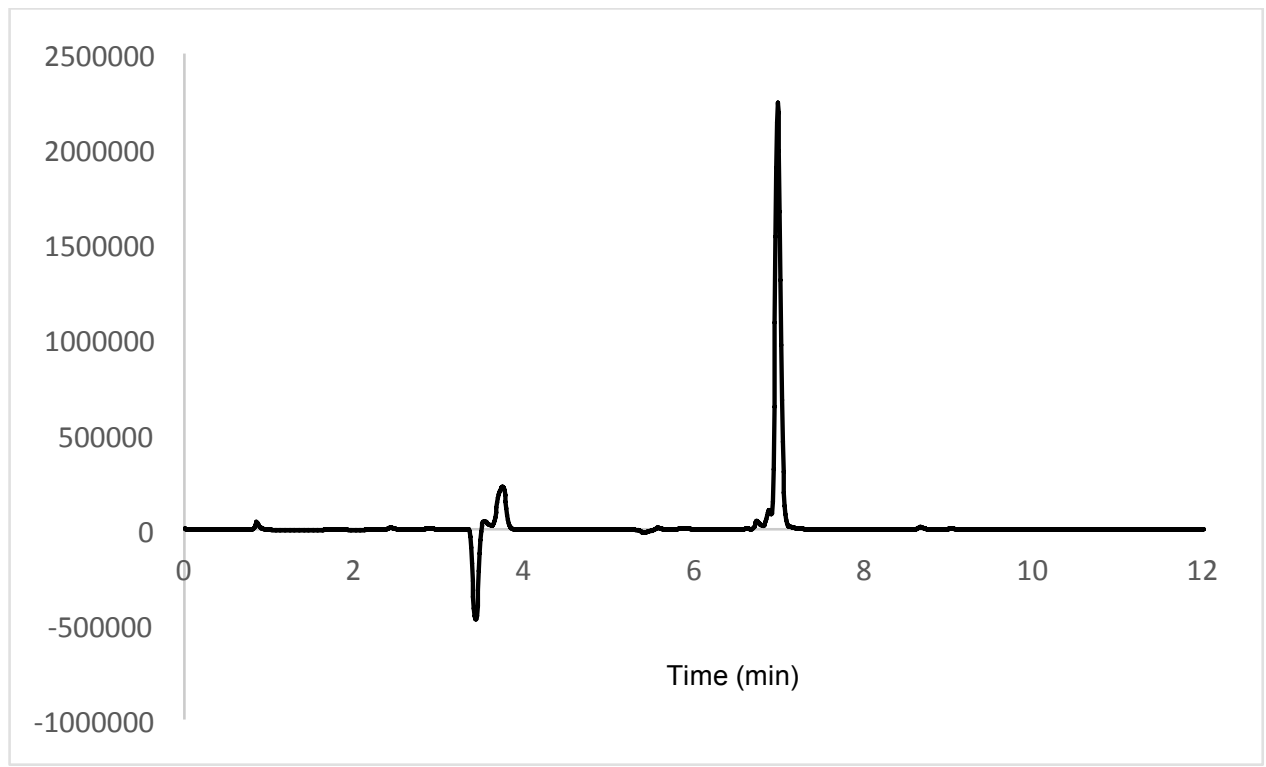

12

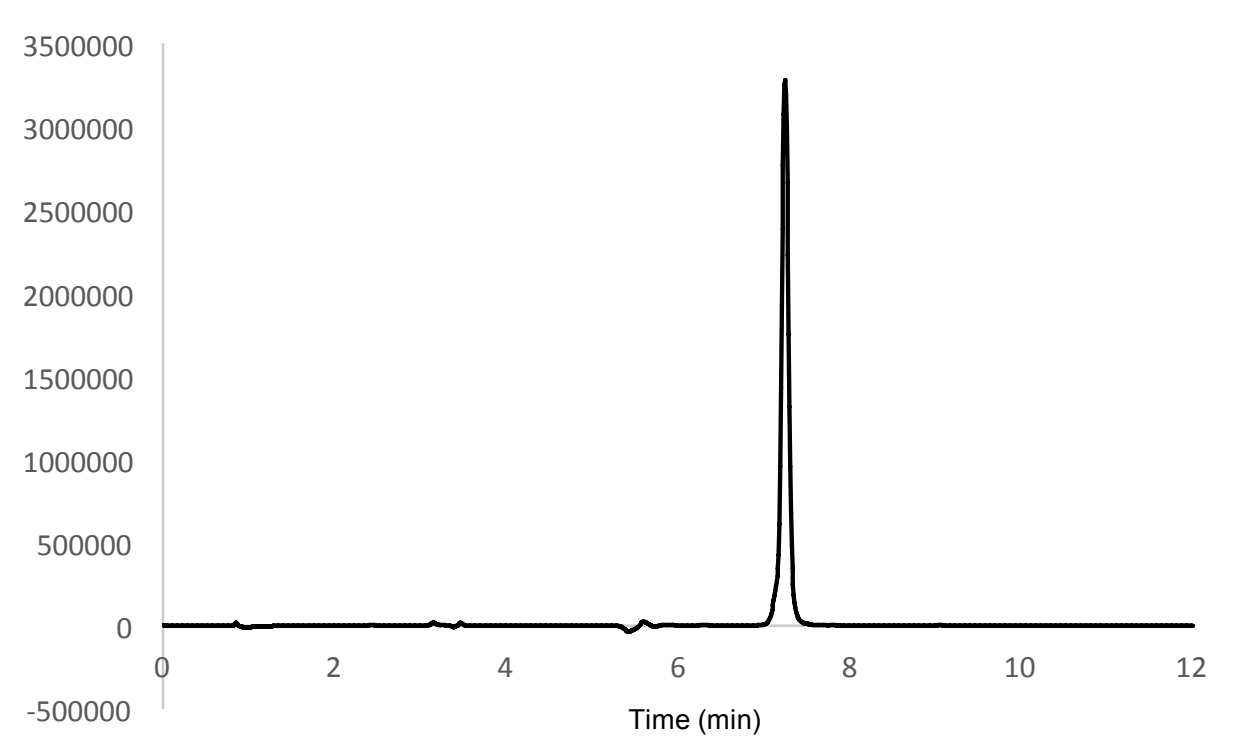




\section{References}

(1) O’Dowd, H.; Kim, B.; Margolis, P.; Wang, W.; Wu, C.; Lopez, S. L.; Blais, J. Preparation of TetraBoc-Protected Polymyxin B Nonapeptide. Tetrahedron Lett. 2007, 48 (11), 2003-2005.

(2) Li, B.; Akin, A.; Magee, T. V.; Martinez, C.; Szeliga, J.; Vuong, D. V. Syntheses of Dap-3 Polymyxin Analogues via a Tris-Boc-Protected Polymyxin B Heptapeptide. Synth. 2015, 47 (14), 2088-2092.

(3) Silverman, S. M.; Moses, J. E.; Sharpless, K. B. Reengineering Antibiotics to Combat Bacterial Resistance: Click Chemistry [1,2,3]-Triazole Vancomycin Dimers with Potent Activity against MRSA and VRE. Chem. - A Eur. J. 2017, 23 (1), 79-83.

(4) Abmm, D.; Tamma, D.; Kirn, J.; Cullen, S. K. Clinical and Laboratory Standards Institute (CLSI). Performance Standards for Antimicrobial Susceptibility Testing. 30th Ed. CLSI Suppl. M100 2020, Wayne, $P A$ 